\title{
Erratum: A review of approaches to assessing scour current velocity around existing structures
}

Adeniyi Aje and Ahmad Khattab

The publisher regrets that errors appeared in this paper when it was published online ahead of print and in Proceedings of the Institution of Civil Engineers - Forensic Engineering 170(2): 84-99, http:// dx.doi.org/10.1680/jfoen.16.00035.

In Equation 52, the final term should be $U_{\mathrm{iv}}$, not $U_{\mathrm{i}}$. In Equation 54, the first operator should be a minus symbol, not a plus symbol. The correct equations are as follows.
52. $U_{\text {ih }} \approx U_{\mathrm{i}}=U_{\mathrm{iv}}$

54 $V_{\text {fh }}=\left[U_{\mathrm{i}}^{2}-\left(\frac{d_{\text {rock }}}{Z} \frac{C_{\mathrm{D}}}{C_{\mathrm{M}}} \frac{A_{\text {rock }}^{\prime}}{V_{\text {rock }}}\right) U_{\mathrm{i}}^{2}\right]^{0.5} \quad($ Equation $8 \mathrm{a})$ 